\title{
Just Another Tool? IT Pedagogy and the Commodification of Education
}

\section{Torin Monahan}

This article investigates the social relations being produced through the incorporation of information technology (IT) into educational practices. Drawing upon field research with the Los Angeles public school system, the article analyzes social relations in three technology classrooms, discusses gender and ethnic inequalities with technology, and documents the kinds of educational technology programs that teachers and administrators find valuable. Rather than IT being an apolitical tool, these examples illustrate how technologies operate within larger ideological systems, linking students and public institutions intimately with globalization processes of privatization and commodification. In conclusion, an alternative framework for technology pedagogy is introduced, one that confronts the politics of technology by perceiving information technologies as social media rather than simple tools.

KEY WORDS: commodification; globalization; information technology; Los Angeles; pedagogy.

We cannot begin a reform of education unless we first understand that neither individual learning nor social equality can be enhanced by the ritual of schooling. We cannot go beyond the consumer society unless we first understand that obligatory public schools inevitably reproduce such a society, no matter what is taught in them... In a schooled world the road to happiness is paved with a consumer's index.

(Illich, 1971, pp. 55-58)

[T]he much vaunted "flexibility" of the new forms of global economy involve not simply new forms of connection but new forms of disconnection as well.

(Ferguson, 2002, p. 141)

Torin Monahan is the author of the forthcoming book Globalization, Technological Change, and Public Education (Routledge, 2005). He is Assistant Professor of Justice \& Social Inquiry at Arizona State University. With training in the field of science and technology studies (STS), his scholarly research focuses on the design of information technology infrastructures and their associated political and social ramifications. He conducts ethnographic research on telecommunication networks in schools, surveillance and biometrics systems in public places, and the techno-spatial transformation of cities. Address correspondence to Torin Monahan, Arizona State University, School of Justice \& Social Inquiry; e-mail: torin.monahan@asu.edu. 


\section{INTRODUCTION}

"Computers are tools, just like pencils." This is the statement echoed on the lips of most technologists, teachers, administrators, and policymakers in L.A. Unified School District. It is a deceptively simple statement that smooths over many of the chaotic elements of the current "Information technology (IT) revolution" of Internet connectivity in public education: infrastructure construction projects, organizational restructuring, technology-driven curricular changes, enhanced security systems, acceptable use policies, increased costs and dependencies, and altered instructional modalities (Monahan, 2004). If the power of the pencil lies in its simplicity, versatility, and mobility, then comparing computers to pencils suggests that computers adapt somewhat synergistically to individual needs and, by implication, that the use of computers is largely disconnected from systemic dependencies, politics, and social relations. Drawing upon a year-long ethnography of technology use in the L.A. public school system, this article challenges these assumptions by arguing that the current state of technology-based instruction in L.A. Unified reinscribes larger social transformations underway with globalization, demanding a great degree of individual flexibility and supporting the ongoing commodification and privatization of public institutions.

To begin this inquiry into the implications of IT instruction in L.A. Unified, this article first provides an overview of Dewey's progressive philosophy of education as a touchstone for analyzing current technology practices in school classrooms. Next, it discusses IT pedagogy in relation to perceptions of gender and racial inequalities in the District, drawing attention to the risk of occluding difference under commodification regimes. It then documents what pedagogies my interviewees and informants find valuable and evaluates these exemplars in relation to the ambitions of progressive education. The combination of these elements - technology practices of classroom instruction, perceptions of social inequality, and expressions of value - reveal that the goals of public education as an institution are becoming increasingly narrow in spite of the liberating promises of globalization and information technology. As a corrective, I offer a conceptually different approach to technology pedagogy, one that perceives computers as media instead of tools, and one that introduces elements of "structural flexibility" into what are currently ideologically inflexible regimes in public education.

\section{PHILOSOPHICAL BACKDROP}

In the originative work of educational philosophy, Democracy and Education (first published in 1916), Dewey advanced a conception of learning as 
an eminently social practice necessarily situated in a material environment. Rather than viewing learning as a uni-directional transference of knowledge, his progressive educational approach stressed action, communication, participation, and experience; the end-goal being the continual process of individual growth directed toward social aims. Education conceived of as a social practice opened up inquiry to the many networks that play upon institutionalized public education and are reproduced by it, including class differentiation, market demands, and ideas of progress. The key threats to progressive or constructive education, Dewey (1944) opined, are the myriad external aims imposed upon learning processes, eclipsing student-centered growth and development:

The vice of externally imposed ends has deep roots. Teachers receive them from superior authorities; these authorities accept them from what is current in the community. The teachers impose them upon children. As a first consequence, the intelligence of the teacher is not free; it is confined to receiving the aims laid down from above. Too rarely is the individual teacher so free from the dictation of authoritative supervisor, textbook on methods, prescribed course of study, etc. that he can let his mind come to close quarters with the pupil's mind and the subject matter. This distrust of the teacher's experience is then reflected in lack of confidence in the response of pupils... In education, the currency of these externally imposed aims is responsible for the emphasis put upon the notion of preparation for a remote future and for rendering the work of both teacher and pupil mechanical and slavish. (p. 109-110)

This is a remarkable passage, for it expresses quite clearly (almost a century ago) many of today's sentiments, especially held by teachers, toward standardized tests, curricular benchmarks, and other mandated impositions such as computer-use in classrooms.

In effect, the formulation of learning as a social practice rendered visible the many external pressures that Dewey then sought to mitigate in order to preserve the unencumbered growth process of individuals. But what Dewey did not pursue was the necessity of ideological impositions by means of the larger social context that educational institutions operate within and cannot be divorced from. This is the lens that Illich (1971) selects for his condemnation of all institutionalized learning. For Illich, educational institutions are inimical to individual growth because they perforce function as products of capitalist society that, in turn, produce consumers rather than life-long learners. Apple (2000), Burbules and Torres (2000), and others have since noted how globalization penetrates into public education through the combination of certain rationalities, both neoliberal (e.g., privatization, vouchers, flexible and docile students) and neo-conservative (e.g., standards, 
accountability and traditional values), leading to the overall "depoliticization of life." Under globalization rubrics, Apple explains, the domestic world is considered "private" and therefore not political, and the public world is considered "economic" and therefore not political. This emerging depoliticized world, propagated through education, proscribes not only the kind of progressive education espoused by Dewey, but also insidiously eliminates democracy by denying legitimate public space for discussion and critique.

Placing the functions and configurations of educational institutions within this expanded political and economic universe does not deny once-and-for-all the constructivist aims of progressive education, but it does introduce a series of complex interrelations that pedagogical ideals must operate in conversation with, and it does invite the tracing (and perhaps erasing and redrawing) of "external impositions" that always exist within schools and social relations. This holds true, more than ever, for the redesign of educational spaces and practices through the introduction of information technologies. For IT is not only a means of global expansion, it also represents a system for linking students and public institutions intimately to globalization processes, thereby reproducing and reinforcing rationalities of global competition and interconnection. Given this encompassing political orientation, the question posed here is not so much "Do computers work?" but "What social relations do they produce?"

\section{CLASSROOM PEDAGOGY AND IT}

Following from Michel de Certeau (1984), who grouped practices into "tactical" and "strategic" categories (the former being improvised and transient appropriations of spaces, and the latter being planned creations of durable and disciplinary places), this section describes and decodes three everyday tactical uses of technological spaces in L.A. Unified schools. The examples, which I label "disciplinary scare tactics," "isolation and social disconnect," and "panoptic flexibility," convey only some of the many uses of computers in L.A. Unified, but based on my research, they are representative examples. They are chosen to direct inquiry into the tacit curricula or unanticipated learning - rather than intentional pedagogy - that takes place in IT classrooms. This tacit curricula, at least in these examples, points to a troubling connection between neoliberalism and public education.

\section{Practice I: Disciplinary Scare Tactics}

A group of thirty students, followed by their teacher, file into the computer lab at an inner-city L.A. high school (see Figure 1). In this windowless 


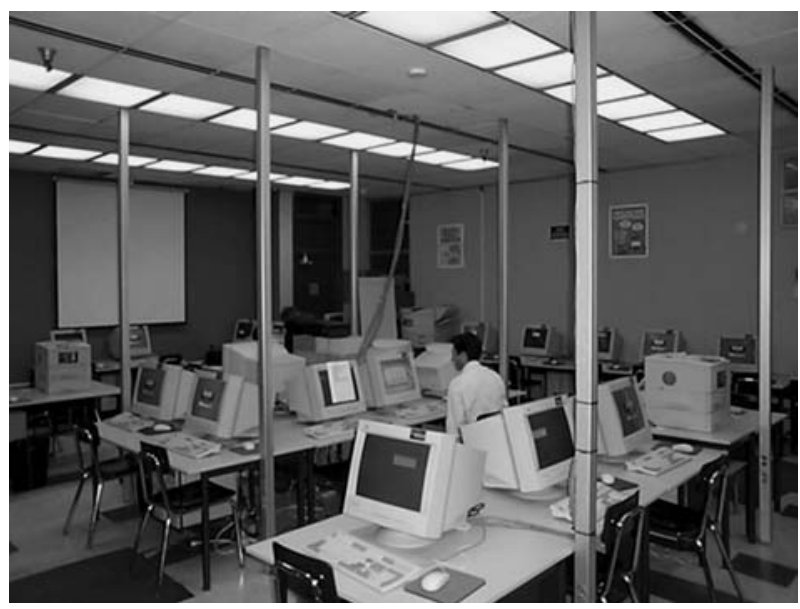

FIG. 1. Computer lab at inner-city high school.

room housing 38 computers, one group of tables with desktop computers forms a small island in the middle of the room while the rest of the lab's furniture and equipment hugs the walls. Blue snakes of CAT5 data cable descend from the drop ceiling, wrap themselves around trellised power conduit, and connect computers to a local area network (LAN). The walls are painted pastel shades of mauve and blue-grey and display colorful motivational posters such as "cheer up!" and "writing is nothing more than a guided dream."

As students take their seats, their first time in this lab, the school's technology coordinator emerges from the doorway connecting his office to this room. The man is a tall and imposing figure with wispy white hair, and his voice bellows out over the heads of the students as he begins his ritual scare speech, scripted more to instill fear and caution in occupants when they are around the expensive equipment than to communicate specific rules of conduct. He makes a series of rapid-fire points

- Because this lab's equipment is paid for by federal dollars, students will be prosecuted under federal laws, which are harsher than state ones, for any acts of vandalism or theft.

- Thirteen people have been sent to jail or detention centers in the past year.

- The minimum jail sentence for those under 17 is four months; for those 17 and over, it's six months.

- No liquid, food, gum, or make-up is allowed in this space. 
- If you play computer games or install programs on computers, even on your own laptop (which no students in this impoverished school own), you will be sent to another high school.

- The surveillance cameras in the lab (tucked away in the corners of the ceiling) will watch you at all times.

During this speech, English as a Second Language (ESL) students pay very close attention; others chuckle nervously, whispering to each other that it is not true. The technology coordinator reads their body language and assures them that he is dead serious and that he is telling them this for their own protection. I question him later about this approach, and he confesses that the point about playing games is true, but only two people have been jailed, and that was an inside job of stealing equipment. When I suggest a communal approach of "let us protect what we have," he asserts that such a tactic would work only for "good kids," but "bad kids" want to damage what any authority figure holds dear.

There are several lessons, other than the intended one of protecting machines, that students can learn from such disciplinary experiences. As students told me in interviews, they learn that computers are highly valued, perhaps more so than students, and that students, too, must value and respect property, even if the property is intended for their use. I speculate that they also learn that their proper mode of comport is one of passivity, acquiescence, and self-discipline, not exploration or experimentation. Finally, it appears to me that they learn that they are not trusted to adhere to stated policies or to be presented with the real consequences of breaking rules.

Given the many potential lessons communicated in this one example alone, which is replicated in many forms throughout the day, it is not surprising that the students who do come to class appear unenthusiastic. Many other students in this school of over 4,000 decide to roam the hallways and the heat-baked asphalt grounds behind locked gates and tattered barbed-wire instead of attending classes, so that hundreds are physically present at school but otherwise "absent" during any given period. The exception to this migratory pattern occurs during testing and attendance weeks, when school performance is gauged and budgets determined, respectively; at these times, teachers and staff routinely round-up wandering students and confine them to classrooms. Aside from these few days throughout the year, administrative pressure is not exerted to put students in classes, and most teachers and staff members feel that it is not their responsibility to engage in what they see as policing work. This is just-in-time education, but it is calibrated to institutional needs, not to student learning or growth. 
Lessons of discipline, passivity, and apathy may not serve students well for individual growth, yet these lessons do prepare students, as future workers, to accept their plight as low-skill, low-wage, low-benefits, and low job-security laborers. These lessons cultivate states of democratic illiteracy, where students maintain unfamiliarity with any concrete manifestation of democratic processes or with conceptions of the public good. Finally, students acquire appreciation for the value of commercial products and a respect for private property. In these ways, the global economy is supported by the human capital of students socialized in public education.

\section{Practice II: Isolation and Social Disconnect}

On Valentine's day in the same school computer lab, a teacher ushers in her class to work on the practical and imaginary task of mapping out their college schedules (even if many will not be going to college). Once the students begin the assignment, she promptly leaves the room to take a break and does not return for the rest of the period. A college teaching assistant (TA) is watching the equipment from the next room, but besides him and me, no other adults are present, and no one is instructing or assisting the students. The TA relates that this is a common occurrence: teachers use the computer lab as a "free period" for themselves. Meanwhile, most of the male students talk, while the female students use the computers to make Valentine's day cards for their boyfriends.

During another period, a different teacher brings in her class and insists, even though there is more than enough room, that all other students in the lab leave (i.e., those who are there during their free period). She then orders one of the student Tas - she does not even know his name - to patch her computer's image through the overhead projector. Soon, students in this class are pecking away at their keyboards with one or two fingers, busily transcribing previously handwritten papers. The hawk-like teacher homes-in on one black student who is sitting at his machine and not typing anything. She says, "The printed assignment is due at the end of the period, so you'd better get to work on your bibliography." He abrasively informs her that he doesn't have any sources because he was absent from the previous class. She curtly responds, "Tough!" and then walks away, leaving the student to mumble, "Fuck you, bitch," under his breath.

In one final example from the same computer lab, students avidly copy images from Microsoft's encyclopedia program Encarta and paste them into Microsoft's Powerpoint presentation program. This is part of a larger "research" project on notable historical figures, and every time these students come to the lab they work on cutting-and-pasting all period long. One of them tells me that these Powerpoint exercises do not work because he never reads 
what he is copying or discusses it with anyone; his project is a series of disconnected images. It would be much better, he continues, if students had to present the material to the class or engage in collaborative group projects. After class, the teacher tells me that students work better in the lab than in regular classrooms because they are obviously engaged and busy, and if they fail to learn anything else, then at least they will know how to use computers. When I ask whether they share their reports with each other, he shakes his head despondently, saying that such presentations would be a waste of time because they are never good enough for others to learn from.

What can these three examples from the high school computer lab tell us about globalization and education? In cities such as Los Angeles, one dimension of globalization is the establishment of high-tech and financial industries that then require vast service sectors of unskilled jobs to support them (Sassen, 1991). These examples can be read as preparing students for this demand through a tacit curriculum and "built pedagogy" (Monahan, 2002) instructing them to fend for themselves and to appear busy, regardless of the subject matter. These examples offer insight into the constraints and doublebinds placed upon all actors in public institutions; institutions that are struggling to fulfill service missions within a hostile climate of privatization. The teacher who vacated the room was tactically poaching off of an educational system that, as a rule, overworks teachers and undervalues their labor. In a profession where content and responsibilities are increasingly pre-scripted, the establishment of a computer lab granted her freedom to maneuver in selfselected ways but resulted in the neglect of students. The teacher who assumed a harsh disciplinary tone with students erected a rigid emotional barrier to preclude intimacy and defer conversations about the purpose or relevance of mindless computer activities (which are disparagingly called "drill-and-kill" by District technology coordinators). Such a stance alienated students but served to protect her from a possibly demoralizing self-reflexive appraisal of her own teaching or from a recognition of the constricted opportunities for effective teaching and learning within the public school context. The last teacher was outwardly more self-aware than the first two, but was unwilling to trust students to pursue work in conversation with their classmates. Thus, not only were their collected cut-and-pasted images disconnected, but so were students artificially isolated from their peers, or from a full range of individual growth within this social context.

\section{Practice III: Panoptic Flexibility}

In a computer lab at an old high school in the shadeless and hot South Central Los Angeles, two teachers preside over a massive room of 54 students, each hunkered down in front of their own bulbous, blue Apple Imac 
desktops. The two male teachers are perched on a riser in the "front" of the classroom overlooking all the monitors while students sit with their backs to the instructors. In an uncommon display of design foresight, both teachers and students face a series of large windows at the "back" of the classroom, such that a sense of outside connection is established, but the glare from the sunlight does not reflect off of computer screens (see Figure 2).

I enter this space as a class is already in progress and observe students working quietly and individually on the computers. One of the teachers directs me up to the riser and explains to me that the students in this room are in two separate classes (or "tracks") and are therefore working on different projects: introduction to computers in the first class and webdesign, digital art, or other self-selected topics in the second. He then enumerates the many elements of control that are exercised over student instruction, from meticulously constructed web-based lessons, to teachers' superior visibility of all student activities, and not least of all, the technological dominance over students' computers through the network software. Proudly, yet purposefully, he demonstrates "taking over" the machines of a group of students through his computer connected to the network. Students cry out "hey!" and turn around to see why they have been interrupted in mid-task. Having their attention, he explains to them a procedure for adding shadows to buttons in web pages; he then executes the procedure on his machine with the sequence of mouse-drags and clicks faithfully reproduced on each of these students' monitors; finally, he relinquishes control over their attention by disengaging his virtual network

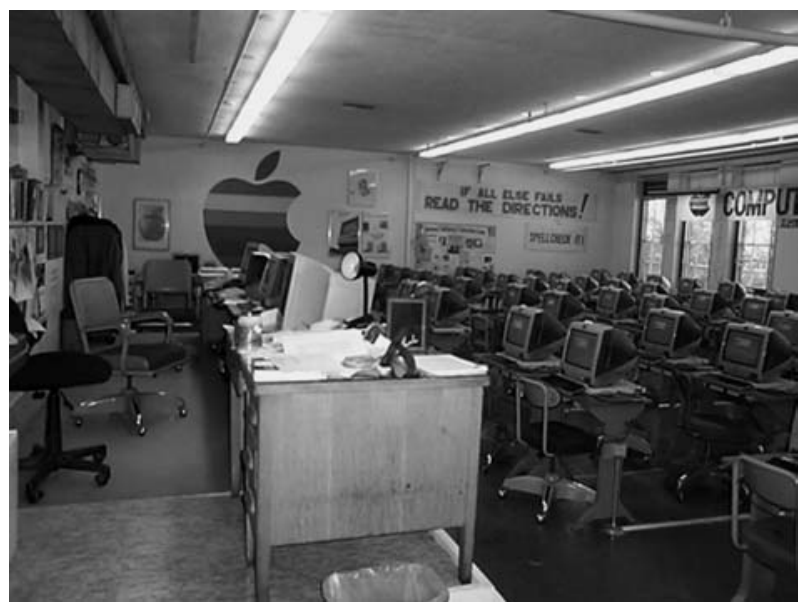

FIG. 2. Panoptic computer lab. 
tentacles from their Imacs. Throughout this demonstration, the rest of the class continued unperturbed on their previously assigned work. "It's not 1984, even though it looks like it!" the teacher concludes.

Unlike the other practices described above, this activity did not abandon students or directly alienate them; it instead created a strong sense of structured discipline, with active classroom control ensured through technological prostheses. The design of this space obviously lent itself to such interactions, but the addition of teachers who seemed as compassionate as they were firm, and the apparently "cutting-edge" lessons that students were encouraged to pursue (e.g., making web pages), created a productive amalgam for individual-based learning.

The unintentional lessons are a bit harder to decipher. The panoptic technologies at work here may require an educational individualization, because the eye-in-the-sky that can swoop down to monitor, control, or direct you is most effective when there is only one "you" to monitor, control, or direct. Thus, students may be grouped for management purposes, but not for collective activities based on social interaction. The disciplinary learning-scaffolding here may afford self-motivated, individual activities, but it simultaneously forecloses non-sanctioned actions within the classroom. This socio-technical space teaches students that they, too, can gain technological (and by extension economic) power, provided that they work diligently alone and discipline themselves from the temptations of social distraction.

This tacit curriculum of panopticism reinforces an ethic of self-discipline and undistracted labor while simultaneously developing subject positions that embrace external monitoring and control (Foucault, 1977). These external forces, unannounced and therefore always anticipated, mobilize fear and promises of material gain to elicit acceptable behaviors of individual work and collective silence. As Lyon (2001) suggests for other contexts, subject positions that are adopted in response to conditions of ubiquitous surveillance perfectly suit the labor needs and political indifference of the global economy.

Together, the three types of IT pedagogical practices described in this section paint a range of disciplinary activities within globally insinuated, technological spaces, where in each case, technology modulates power differentials between individuals in varied social positions (i.e., students and teachers). These technological "tools," in other words, reconfigure social relations, potentially removing control from teachers who then respond by transferring disciplinary functions to the technology (security cameras, network administration programs, and mindless rote exercises) or by reasserting (or abandoning) social control through alienation tactics (scare speeches, abrasive attitudes, or absenteeism). Importantly, it is the value 
attributed to technologies and their configuration within spaces that lends them this disruptive potential; as technologies become important actants in these social worlds (Latour 1987), they do not so much shift power to students or to teachers as they leach (or are delegated) power within these contexts. The net effect, however, is one of discipline, individualization, and social disconnect. Learning as a social activity of individual growth is subordinated to (but not necessarily supplanted by) the globalizing rationalities that network technologies embody and reproduce.

I have sought to show how the lessons that students receive in technology classrooms are shaped by the combination of social practices, technical valences, and spatial designs. But the ideologies crafted in schools are surely inflected by those circulating beyond the school yard. The claim here is that what may be poor pedagogy for individual and social growth is ideally suited for the production of workers who can meet the needs of global capital without challenging the political status quo.

\section{INTERPRETATIONS OF INEQUALITY}

The educational practices of IT may familiarize students with new workplace training and labor routines in the post-Fordist era, but globalization researchers have also documented new relations of gender, race, and class that deserve exploration in the domain of public education. For instance, Ong (1991) describes how the practices in Chinese, Malaysian, and South Korean factories and sweatshops reveal both the persistence of patriarchy and new forms of women's resistance, made possible by configurations of postmodern capitalism that rely on the skills (and low wages) of women in workplaces. Likewise, Valle and Torres (2000) discuss media tactics of non-oppositional resistance used by Latinos in L.A. to successfully campaign for union jobs at the new Staples Center sports arena; they succeeded by operating within the logic of global development, and by leveraging that development imperative to their advantage. Also taking Los Angeles as a place of study, Keil (1998) documents the rise of "insurgent civil societies" that coalesce members from many different class and racial groups to contest destructive trends of global capitalism; these collectives are tied together more by topical concerns (e.g., homelessness and environmental degradation) than by social identity. This section analyzes perceptions of race, class, and gender inequality in L.A. Unified, specifically in regard to information technology, to see what insights public schools can offer to this picture of shifting relations within globalization.

If IT in public school systems is supposed to help students overcome structural disadvantages such as poverty, unequal opportunity, or institutional racism (which is in fact the discourse of "digital divides" and 
"universal access" that, to a certain extent, propels technological policies and laws), one would expect individuals in L.A. Unified to have developed nuanced and critical understandings of race, class, and gender in a technological context. For the most part, judging from all my interviews and conversations, this is not the case. As a general summary of responses, interviewees were quite comfortable talking about class issues and the promises of technology for correcting class inequity; they were slightly less comfortable but still vocal in discussing differing levels of technological acumen and proficiency between men and women; but, with rare exceptions, articulations of race or ethnicity were completely absent, and through their guarded responses, interviewees subtly let me know that issues of race were off-topic, inappropriate, and likely irrelevant. Because this was the most interesting "finding" within these three categories, let me begin by offering an illustration and an interpretation of it.

The following passage from an interview with an African-American business teacher typifies this penchant to redirect race-oriented questions back to issues of class:

\section{Do different ethnic groups use technologies in different ways?}

I think they would use it in different ways depending upon their exposure, depending upon their educational levels, because a lot of times it's not used because they don't know how, you know? So it's going to depend upon how well you prepare them and they know what they're doing, and then they can see the uses of technology - how valuable it is to use it. Otherwise, they would make no difference. It just depends upon the exposure of the person. Maybe a person in a higher economic situation would have computer exposure much quicker than a person in a lower economic area. They wouldn't have it available to them, so they wouldn't know how to use it as well as a person up here [holds her hand up high]. So, I don't think it's ethnic or not; I think it's exposure. It's exposure and use of it-"know how."

Okay. So if there is an ethnic difference in use of technologies, you would attribute that more to socio-economic status -

Yes, not the other way around.

This teacher recognizes the link between race and class, but attributes any lack of access or any differences in patterns of use to degrees of technological "exposure," not to ethnic identities or racial biases. Put otherwise, as social categories, race is subordinated to class. This is, at least, the surface story that I am told, and the perception of technology as economically enabling helps sustain this version. 
It is not surprising that questions concerning technology and ethnicity gravitate back toward class when technologies are perceived almost entirely as economic enablers. One possible explanation for interviewees' reluctance to discuss race issues is the ultra ethnically diverse context of L.A., with its frequent racial clashes (mostly undocumented altercations) and its constant threat of conflict eruption. This environment sustains a palpable racial tension, like a harmonic overtone that all can hear if they choose to listen. In places of heterogeneity and disenfranchisement, like public schools, it is impossible not to register this note, to heed its warning and attempt to channel it into productive, if fleeting, resolution. Questions like mine about how students from different ethnic backgrounds utilize or relate to technologies aggravated this implied balance and expected silence, and they violated some unspoken rule about keeping demons at bay by not naming them. Thus, my interlocutors avoided giving me vocal feedback by shifting the conversation to the much safer issue of class.

On another level, the shifting of race-based analyses to issues of class evokes entrenched ideologies of universalism in U.S. public education. Public schools serve as official sites for the cultural drama of equality of opportunity, regardless of the particularisms of race and ethnicity, and actors perceive class differences in education as legitimate outcomes of a meritocractic competition that rewards talent and work over biological difference. Class is easy to speak about because of its association with such "legitimate" universalism: the production of achieved difference is contingent on blindness to ascribed difference. Thus, diverting discussions of race to issues of class is an important part of the educational ritual of universalizing the particular. Recognizing race means coming to terms with what my interviewees perceive to be the illegitimate intrusion of particularism into the universalizing practices of public education.

There were a few exceptions to this pattern of deflecting volatile race issues, but these anomalous statements were very general in nature and doubly and triply qualified to avoid any misunderstanding on my part or any wrongful attribution of "racism" to their assertions. In one instance, a Caucasian teacher explained to me what he called "the cultural winds" at play in student academic (including technological) achievement: Latino families push their children toward trade training with the aim of them getting jobs, while Latino peers are neutral to the issue and so present no competing cross-currents for this goal. African-American families, he explained, less forcefully motivate their children toward vocational training, and these students' peers are determinedly anti-intellectual (e.g., harassing those who carry backpacks or books), presenting a strong counter-wind to individual advancement. This theory of cultural cross-currents offers insight into some of the reasons behind behavioral differences, but it simultaneously 
eschews any conversation of ethnic or racial identity in relation to differences in technology use.

Discussions of gender and technology, by contrast, yielded much more colorful and passionate opinions and convictions. Given the widespread associations between high technology and sexiness, it is not surprising to observe how technological practices in schools are both gendered and are gendering. To this end, this next passage, taken from an interview with a woman who is chair of the business department at an L.A. high school, is analyzed for its gender stereotypes and sexual undertones. I began by asking her whether computer use at the school reproduced stereotypes of men using technologies more than women. She responded:

I kind of think that's going to be a 'has-been.' I think that it will get better. But basically, because men are more, initially more manipulative -

Just manipulative, period?

[both laugh]

Yeah, period - with their hands. And that's one of the things that men have always been famous for, to fix things. And I think they're "fix-its." Men are "fixits." Women are usually more compassionate; they're the ones that keep things together, and all that. But men, they usually take things apart and put 'em back together.

\section{Tinkerers?}

Yeah, they're tinkerers. But I don't think that will stay that way. I think that women will enter into the market and I think that they will do an acceptable job, because women have something that men don't have: "stick-to-it-ness." They will stay there until it's done. Men will kind of tinker and go on. And I think that quality will help us [women] in that area... I think [men] will have some competition.

\section{Because women will start to become more technically proficient also?}

Right. And I think men will have competition in that area, and I'm sure they're already getting it, from the women, but they're going to have more, because women seem to stay with it longer. They'll stay with anything longer, than men. And men want to get it [claps her hands up and down], get it and get gone. But women, because of their perseverance, they're going to give men a really good turn, for those competitive jobs... I think that when these jobs level off, there will be higher jobs, and I think because women have entered into the market, they're going to be in competition for those higher jobs also, and they're going to be right there giving men a headache! [she laughs] 
It is difficult not to read this passage as a play of stereotypes about gender and sexual behavior: men "manipulate" while women tolerate patiently; men want to "get it and get gone" while women want to see things through. However, as the interviewee augurs, difference and inequality are in the past, because in the near future, men will have "competition" from women. Again, particularism is subordinated to a more universalistic interpretation of IT and educational practices, where information technologies are figured as passive, neutral, and gender-neutral tools with potential for leveraging more equitable relations sometime in the future. Of course, the past and the present remain times in which women's subordinate role in society is recognized. Thus, this description signals a tension between IT pedagogy as a machinery of gender neutralization and equalization and as a continuation of longstanding patriarchal structures that link technological progress to masculinity.

To conclude this section, articulations of class differences were the most prevalent responses to questions about inequality and technology. Almost all of them matched the sentiment expressed in the first quote on ethnicity above (socio-economic status determines access or exposure), or they adopted a tone conveying dire, if amorphous, imperatives for equipping students for a global workforce. Technology is interpreted as helping to level the playing field by establishing equal starting points. As one teacher stated as her self-appointed mission: "Make these kids computer literate, so that they can cope and they can compete with other people in the work market." However, the problem with perceiving technologies as only catalysts for competitive individualism is that this symbolically purifies and absolves them of a critical reflective discourse on how they reproduce inequality through their use.

As an indicator of shifting power relations within the global economy, the findings from L.A. Unified indicate a disturbing trend, one of masking possible issues of race and gender differences behind class determinants. This was done perhaps out of fear of aggravating existing tensions or upsetting dominant mythologies about color-blind technologies and equal opportunity for technological empowerment. I do not take the reduction of race and gender to the category of class to mean that these are unimportant distinctions for my interviewees, because especially with race, interviewees were too consistently insistent on changing the topic of conversation. The denotation of their remarks was "this isn't important," but the connotation was "this is too volatile." The issue was explosive not only because L.A. is a city that knows race riots, but also because American schools are stages for the performance of the American dream.

The redirection of conversations about race and gender to class issues makes it difficult to spot discrimination or injustice within existing conditions and to make recommendations for alteration. A current, if general, take on social relations under the IT revolution is that there are dramatically 
fewer women occupying technical positions- $20 \%$ of the IT workforce (AAUW, 2000) - and that poor minority students are more likely to be given repetitive, "drill-and-kill" exercises on computers than their white, affluent counterparts who are given more contextualized assignments (ETS, 1999). Such observations are then manifested in the actual technology practices of students in L.A. Unified where, as noted above, students are placed, more often than not, into instructional situations that teach discipline, individualization, and alienation. Where there are opportunities for students to engage in technical occupations in schools, such as repairing computers or serving as computer lab TAs, they are often economically exploited for this work, and women are systematically excluded from such positions. Thus, as currently configured, information technology in schools may aggravate existing inequalities while reinforcing lessons of their inevitability, in spite of proclamations about equal opportunity.

\section{EXPRESSIONS OF VALUE: SCHOOL ACADEMIES AND ENTERPRISES}

This article has so far advanced a conceptualization of learning as a social practice, has described several trends with IT pedagogy, and has drawn upon field interviews to offer interpretations of inequality with technology. If what Dewey called the "external" pressures placed upon education are necessarily internalized and then reproduced in locally specific ways, as I have argued, then we should try to identify these pressures at their sites of intersection with education in order demystify or denaturalize their effects and implications.

Because determinations of value are often contingent upon systems of exchange that transcend immediate settings, one way to get at these places of intersection is to pay attention to what pedagogical situations become exemplars of economic value and innovation. This section will trace two developments that my informants in L.A. Unified held up as examples of pedagogical success - "academies" and "enterprises" - in order to identify where globalization ideologies overlap with situated educational aims and to what effect.

In L.A. Unified, technologists and teachers admire what are known as "schools within schools," such as "media academies" and "enterprises" located on the grounds of existing high schools and serving as extensions of them. Interested students must apply for these rare public programs and are not guaranteed acceptance. With media academies, once students are accepted, they are given preferential treatment: they take all their "electives" within the academy, usually learning special skills like video-editing or computer animation; they generally have smaller class sizes and more 
exposure to cutting-edge technologies; they have a small cohort of students (about 200) within a larger school of three to four thousand; their core classes are "integrated" such that they learn history, English, and social studies, for instance, while creating their own media productions; they are appointed professional, outside mentors in their field of interest; and, when available, they go on internships during their senior year. Students of high school academies have a $90 \%$ graduation rate, program directors told me, compared with a $60 \%$ graduation rate for all other students in these schools. The programs are, therefore, truly elite within the public school system.

School "enterprises" share a similar positional orientation within schools to that of academies, but these are usually profit-making ventures within schools and are run almost entirely by students (under some supervision). For example, in one enterprise, students manage the building and selling of computers to outside companies, including the installing and maintaining of networks. In another example, students grow food in the school's gardens, make salad dressings, and then sell those products to local supermarkets under the brand "Food from the "Hood!" In discussing the creation of a technology-based school enterprise with one previous director, she asserted that the idea was to involve students in a "real world" venture through the establishment of a separate corporation that operated within a school but outside of school district control. Through legal incorporation, students were promoted to the status of "executives" and "stockholders," and the District was legally unable to take its usual $7 \%$ share of all school donations. Unlike the academies, which are still framed in educational metaphors, the enterprises unabashedly conflate business and educational goals.

These two expressions of "value" within L.A. Unified (school academies and enterprises) each operate at the intersections of internal educational missions and external pressures (where the false internal/external distinction is used simply as a heuristic for investigating learning environments within larger social contexts). The underlying theme that runs through each of these expressions is one of an economic marketplace, defined by a state of competition for scarce resources. School academies and enterprises exist mainly for the sake of preparing students for the marketplace; other kinds of learning undoubtedly take place, but the primary lessons are acquiring technical and/or business skills for individual gain. One grave risk of such an emphasis on preparing students for the workplace, as noted by Apple (2000) and Spring (1998), is the globalization and commodification of education, whereby room for political critique or even for discussions of democratic goals is slowly eliminated. Put otherwise, the prioritization of vocational goals, and the assessment of educational progress in relation to industry, privileges an economic perspective to the detriment of any less economically 
infused learning activities. This is a subtle process that can be seen more readily in the valuing of school academies, enterprises, and high-tech classrooms than in its corollary - the cutting of arts and humanities curricula.

When these economic measures of performance operate as a cultural dominant in L.A. Unified and other institutions, they support what Bromley (1998) has called the "rationalization of public life," as are seen with technology pedagogies that result in experiences of atomization and social disconnect. In the computer classrooms, students' social disconnect as they engage in individual projects and as they exercise panoptic self-discipline shares structural similarity to the disconnect reached by valorizing vocational training programs for their economic accomplishments alone and the disconnect that teachers enact regarding racism and sexism. It is in these and other ways that disconnection becomes the experience for students and teachers; it is what is learned and what is taught, and not coincidentally, it produces subjectivities valued by global capitalism: socially and politically alienated labor forces that are also active consumers.

\section{CONCLUSION: FROM TOOLS TO MEDIA}

This article began with a common expression of computers being tools just like pencils. Given the many ways that information technology pedagogy reproduces and alters social relations in classrooms and further enmeshes both the organization of L.A. Unified and its members in the global political economy, this pencil/computer comparison could be a dangerous oversimplification that obscures the profound changes taking place. In light of the evident social transformations documented here, it makes eminent sense to perceive technologies as political, as components of complex systems that bring about conditions largely beyond our control or comprehension. As Winner (1977) writes:

Is technology a neutral tool to human ends? No longer can an affirmative answer be given without severe qualifications. The most spectacular of our implements often frustrate our ends and intentions for them... Far from being merely neutral, our technologies provide a positive content to the arena of life in which they are applied, enhancing certain ends, denying or even destroying others. (p. 29)

Following from the previous sections' critique of social disconnect resulting from market-based evaluations of educational performance, conceptions of computers as simple tools reinforce this disconnect by deflecting 
questions of implications beyond the classroom and then individualizing learning within the classroom by parsing it into discrete technological performances. Just as valuing education foremost for its workplace training is dangerously limiting, so does the equation of pencils and computers falsely constrict learning possibilities and evaluations of them.

In response to the call for progressive education made by Dewey, a more structurally flexible approach to understanding the role of computers in constructing social relations, identities, and (dis)connections, would be to conceive of them less as tools and more as media that are components of larger socio-technical systems. Media, as McCullough (1996) gracefully presents them, are substances or contexts that mediate human action and may be altered with tools; by mediating, they serve as acts of communication and invitations to interpretation. McCullough writes:

When the tools are complex, when artifacts produced are abstract, or when tools provide the only means of access to the medium (all common conditions in high technology), it can be difficult to say where a tool ends and a medium begins. But we can say that under skilled practice even these tools become transparent, and that a sense of a medium eventually emerges. (p. 193-194)

Media imply an invitation to alteration, but they simultaneously tend toward transparency, which, as I see it, is both their power and their limitation. Transparent contexts for action seemingly enable unhindered action or creation, but that is because the limits and rules of action have become internalized, accepted, and taken for granted. As with jazz music, internalizing the strict rules of structural and tonal form can invite one to push on those rules and to innovate; however, one must constantly both accept that invitation and keep it at bay to avoid the unmusical poles of sterility or cacophony. Through action or play, one must constantly strive to reinvent old rules or create new ones, and the same should hold true for educational computing. Contexts for learning with technology should afford a multiplicity of learning styles and activities, and they should also motivate the reevaluation and re-scripting of the rules for learning (Monahan, 2002).

When analyzing classroom practices with information technology for their learning potential, I find it useful to graph them onto what Haraway (1992) calls a "semiotic square" along the axes of tool-medium and material-virtual (see Figure 3). The use of pencils or similar implements would fall into the quadrant of material-tool; classroom spaces, sounds, stages, canvases, or even the human body are material-media; the kinds of cut-andpaste, document transcription, or rote uses of computers described above fit into the virtual-tool quadrant; and uses of computer programs as media for creation, perhaps for art creation with animation software or composition 


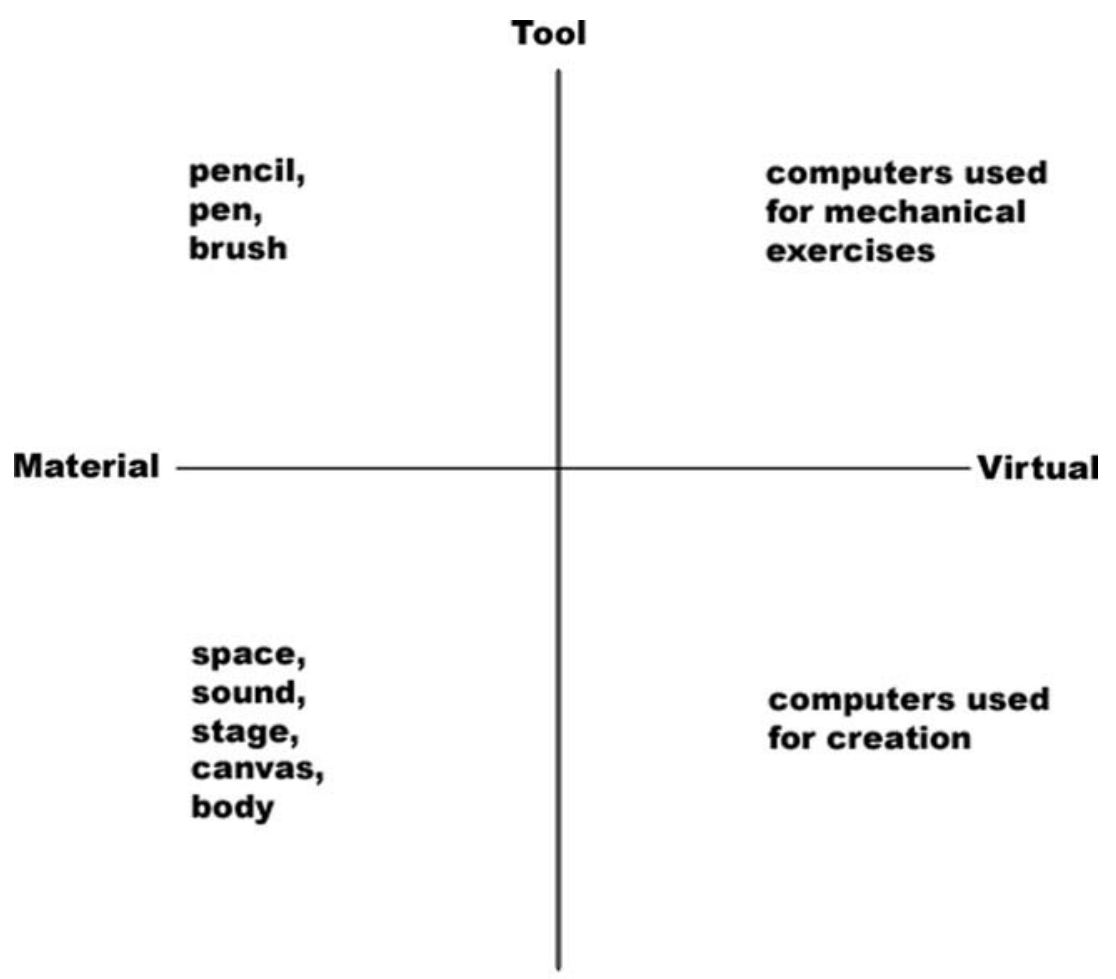

\section{Medium}

FIG. 3. Semiotic square of educational technologies.

with word processing programs would map onto the virtual-medium quadrant. Such categorization definitely depends upon a subjective assessment of situated activities, but it should not be interpreted as a solidification of boundaries between categories - lines exist, but they should be thought of as permeable and transparent, like the media they are intended to describe and ultimately engender.

When computers are thought of as tools, they tend to yield mechanical tasks and situations of social disconnect. But, as a rule, the "media" approach to computers, which perceives them as part of complex systems of interdependencies and as contexts for creative expression and knowledge production, catalyzes empowering learning activities because constraints and interconnections become the explicit terrain for practices.

By implying contexts of constraint, media also draw attention to their embeddedness within larger social milieu, to the field of relations that make 
certain actions possible or impossible, valuable or worthless. That said, any evaluation of learning should fall back upon the question of what kinds of social relations are being produced. As an illustration, the 1984 classroom described above could easily be seen as a virtual medium, yet it clearly produced a climate of social disconnect, isolation, and self-discipline - it is a virtual medium with results that empower in the economic dimension, but probably not in terms of sociality.

Importantly, arguing for computers as productive media does not deny their tool-like properties (any more than student learning denies test score representations of that learning), but it does shift the focus to lines of connection and constraint, such that possibilities remain visible for changing the social fabric that media co-constitute along with human actions and interactions. The concept of media is more flexible in this way, but, not surprisingly, it is avoided by those working with educational technology: not only do media create space for social learning and individual growth, an invitation that can be accepted or declined, but they compel us to face the implications of larger connections and to take responsibility for our roles within those networks. As I see it, it is this daunting ethical challenge that must be accepted if learning is to be taken seriously and if vibrant and enriching social life-worlds are to be preserved under economic globalization.

\section{REFERENCES}

American Association of University Women Educational Foundation. (2000). Tech-Savvy: Educating Girls in the New Computer Age [cited 2001]. Available from http://www.aauw.org/ 2000/techsavvy.html.

Apple, M. W. (2000). Between Neoliberalism and Neoconservatism: Education and Conservatism in a Global Context. In N. C. Burbules and C. A. Torres (Eds.), Globalization and Education: Critical Perspectives. New York: Routledge.

Bromley, H. (1998). Introduction: Data-Driven Democracy? Social Assessment of Educational Computing. In H. Bromley and M. W. Apple (Eds.), Education/Technology/Power: Educational Computing as a Social Practice. Albany: State University of New York Press.

Burbules, N. C., and Torres, C. A. (2000). Globalization and Education: Critical Perspectives. New York: Routledge.

de Certeau, M. (1984). The Practice of Everyday Life. Translated by S. Rendall. Berkeley: University of California Press.

Dewey, J. (1944). Democracy and Education: An Introduction to the Philosophy of Education. New York: Free Press.

ETS. (1999). Does it Compute?: The Relationship Between Educational Technology and Student Achievement in Mathematics. Princeton, NJ: Educational Testing Service. Available from ftp://ftp.ets.org/pub/res/technolog.pdf.

Ferguson, J. (2002) Global Disconnect: Abjection and the Aftermath of Modernism. In J. X. Inda and R. Rosaldo (Eds.), The Anthropology of Globalization: A Reader. Malden, MA: Blackwell Publishers. 
Foucault, M. (1977). Discipline \& Punish: The Birth of the Prison. New York: Vintage Books, Random House.

Haraway, D. (1992) The Promises of Monsters: A Regenerative Politics for Inappropriate/d Others. In L. Grossberg, C. Nelson, and P. A. Treichler (Eds.), The Promises of Monsters: A Regenerative Politics for Inappropriate/d Others pp. (295-337). New York: Routledge.

Illich, I. (1971). Deschooling Society. New York: Harper \& Row.

Keil, R. (1998). Los Angeles: Globalization, Urbanization and Social Struggles. New York: Wiley.

Latour, B. (1987). Science in Action: How to Follow Scientists and Engineers through Society. Cambridge: Harvard University Press.

Lyon, D. (2001). Surveillance Society: Monitoring Everyday Life, Issues in Society. Buckingham England; Philadelphia: Open University.

McCullough, M. (1996). Abstracting Craft: The Practiced Digital Hand. Cambridge, MA: The MIT Press.

Monahan, T. (2002). Flexible Space \& Built Pedagogy: Emerging IT Embodiments. Inventio 4 (1). Available from http://www.torinmonahan.com/papers/Inventio.html.

Monahan, T. (2004). Technology policy as a stealth agent of global change. Globalisation, Societies and Education 2(3):355-376.

Ong, A. (1991). The gender and labor politics of postmodernity. Annual Review of Anthropology 20:279-309.

Sassen, S. (1991). The Global City: New York, London, Tokyo. Princeton, NJ: Princeton University Press.

Spring, J. (1998). Education and the Rise of the Global Economy. Mahwah, NJ: Lawrence Erlbaum Associates.

Valle, V. M., and Torres, R. D. (2000). Latino Metropolis. Minneapolis: University of Minnesota Press.

Winner, L. (1977). Autonomous Technology: Technics-out-of-control as a Theme in Political Thought. Cambridge, MA.: MIT Press. 